\title{
Caffeine alters the effects of bone marrow-derived mesenchymal stem cells on neutrophils
}

\author{
Ardeshir Abbasi ${ }^{1, B}$, Seyyed Meysam Abtahi Froushani ${ }^{1, A, D-F}$, Norouz Delirezh ${ }^{1, C}$, Ali Mostafaei ${ }^{2, B, C}$ \\ ${ }^{1}$ Division of Immunology, Department of Microbiology, Faculty of Veterinary Medicine, Urmia University, Urmia, Iran \\ ${ }^{2}$ Medical Biology Research Center, Kermanshah University of Medical Sciences, Kermanshah, Iran \\ A - research concept and design; $B$ - collection and/or assembly of data; $C$ - data analysis and interpretation; \\ $D$ - writing the article; $E$ - critical revision of the article; $F$ - final approval of the article
}

\section{Address for correspondence}

Seyyed Meysam Abtahi Froushani

E-mail: meysamabtahi@hotmail.com

\section{Funding sources}

This study was supported by the Deputy

of Research and Technology of Urmia University

(Urmia, Iran).

\section{Conflict of interest}

None declared

Received on July 15, 2015

Reviewed on March 3, 2016

Accepted on 0ctober 12, 2017

\begin{abstract}
Background. It has been shown that mesenchymal stem cells (MSCs) express all four adenosine receptors' subtypes, and stimulation of these receptors plays an active role in bone marrow-derived mesenchymal stem cell proliferation and differentiation. The interaction between MSCs and immunocytes, such as neutrophils, has been investigated in some recent studies.
\end{abstract}

Objectives. This study was carried out to investigate the effects of caffeine as an adenosine antagonist on the effects of bone marrow-derived MSCS on neutrophils.

Material and methods. Mesenchymal stem cells were isolated from the bone marrow of rats and pulsed with different concentrations of caffeine $(0.1,0.5$ and $1 \mathrm{mM})$ at different times $(24,48$ and $72 \mathrm{~h})$. Mesenchymal stem cells were co-cultured with neutrophils for $4 \mathrm{~h}$ and the functions of neutrophils were evaluated.

Results. The findings showed that MSCs pulsed with caffeine at low to moderate concentrations preserved the neutral red uptake by neutrophils and established the MSCs' ability to protect neutrophils from apoptosis. Mesenchymal stem cells treated with caffeine increased the phagocytosis of neutrophils and simultaneously diminished the production of potentially harmful reactive oxygen substances, more profound than MSCs without treatment. Nevertheless, a high concentration of caffeine could interfere with some aspects of the crosstalk between MSCs and neutrophils.

Conclusions. These findings may offer new insight into the potential mechanisms underlying the immunomodulatory effects of caffeine.

Key words: neutrophil, bone marrow-mesenchymal stem cell, caffeine

DOI

10.17219/acem/78557

Copyright

Copyright by Author(s)

This is an article distributed under the terms of the

Creative Commons Attribution Non-Commercial License

(http://creativecommons.org/licenses/by-nc-nd/4.0/) 


\section{Introduction}

Caffeine (1, 3, 7-trimethylxanthine) is a natural product and a member of the methylxanthine family of drugs, which can be found in coffee, tea, soft drinks, chocolate, kola nuts, and certain medicines. ${ }^{1,2}$ Caffeine possesses various effects on different body systems, including endocrine, cardiovascular, respiratory, urinary, gastrointestinal metabolism, immunity, and especially the central nervous system. ${ }^{3,4}$ In fact, caffeine is the world's most widely and legally consumed psychoactive drug. ${ }^{3}$ Caffeine is structurally similar to adenosine. Indeed, it is capable of binding to adenosine receptors without activating them, suggesting that caffeine is a competitive inhibitor of adenosine. ${ }^{5,6}$ It also acts as a competitive, non-selective phosphodiesterase inhibitor and, therefore, raises intracellular cyclic adenosine monophosphate. ${ }^{6}$

Mesenchymal stem cells are plastic-adherent, fibroblastlike, and multipotent non-hematopoietic progenitor cells that differentiate into various mesenchymal lineages, including bone and cartilage. ${ }^{7}$ Mesenchymal stem cells also showed a potent immunoregulatory activity, which can be a worthwhile strategy for the treatment of autoimmune diseases and graftversus-host disease. ${ }^{8-10}$ It has been observed that the MSCs' functions are under the control of a large number of signaling systems. ${ }^{11-13}$ Interestingly, it has been shown that MSCs express all four adenosine receptors' subtypes, and stimulation of these receptors plays an active role in bone marrow-derived mesenchymal stem cell proliferation and differentiation. ${ }^{14}$

The interaction between MSCs and immunocytes, such as neutrophils, has been investigated in some recent studies. ${ }^{15,16}$ Nonetheless, there is no information about the role of caffeine on the crosstalk between MSCs and neutrophils. The current survey was set out to investigate the effects of caffeine on the crosstalk between bone marrowderived MSCs and neutrophils in rats.

\section{Material and methods}

Dextran was bought from Fresenius Kabi (Verona, Italy). Fetal calf serum and Dulbecco's modified Eagle's medium (DMEM) were purchased from GIBCO/Life Technologies Inc. (Gaithersburg, MD). Moreover, caffeine, nitro blue tetrazolium (NBT), natural red (NR), dioxin, dimethyl sulfoxide (DMSO), tetradecanoyl phorbol acetate (TPA), 3-[4, 5-dimethylthiazol-2-yl]-2, 5-diphenyl tetrazolium bromide (MTT), and phosphate-buffered saline (PBS) were obtained from Sigma-Aldrich (St. Louis, MO). In addition, May-Grunwald-Giemsa stain was ordered from Merck (Darmstadt, Germany).

\section{Isolation and proliferation of mesenchymal stem cells}

Mesenchymal stem cells were isolated as described elsewhere. ${ }^{17}$ In brief, bone marrow was aspirated from the tibias and femurs of deeply anesthetized Wistar rats. After 2 washings, the cells were plated in $75-\mathrm{cm}^{2}$ tissue-culture flasks with concentrations of 0.3 to $0.4 \times 10^{6} \mathrm{cells} / \mathrm{cm}^{2}$ in the DMEM medium, supplemented with $15 \%$ fetal calf serum. The cells were incubated in a humidified $5 \% \mathrm{CO}_{2}$ at $37^{\circ} \mathrm{C}$. Four days after primary culture initiation, nonadherent cells were removed and adherent cells were fed every other day. Mesenchymal stem cells were removed by trypsin/EDTA when the cultures reached $80 \%$ confluence. The cells were counted and passed in 1:3 ratios (about $1.5 \times 10^{6}$ cells $/ 75-\mathrm{cm}^{2}$ flask). Cell passage was done up to subculture 3 . Then, MSCs were incubated with different concentrations of caffeine $(0.1,0.5$ and $1 \mathrm{mM})$ at different times (24, 48 and $72 \mathrm{~h})$. Afterwards, the medium was aspirated and cells were washed three times with PBS.

\section{Neutrophil isolation and incubation with mesenchymal stem cells}

Blood samples were isolated under anesthesia by cardiac puncture in sodium citrate. The blood was centrifuged and the buffy coat was subjected to dextran sedimentation $(1 \% \mathrm{w} / \mathrm{v})$, followed by centrifugation on a Ficoll-Hypaque density gradient. The plasma and the mononuclear cell layer were removed, and erythrocytes were eliminated using hypotonic lysis. The neutrophils were washed and suspended in DMEM. ${ }^{11}$ Following this procedure, the purity of neutrophils was $95 \%$.

For co-culture experiments, $2 \times 10^{6}$ neutrophils were added to each well of 24-well flat-bottomed plates, containing $2 \times 10^{5} \mathrm{MSCs}$ and incubated for $4 \mathrm{~h}$ at $37^{\circ} \mathrm{C}$ in a moist atmosphere of $5 \% \mathrm{CO}_{2}$. Afterwards, the neutrophils were isolated and used for the next experiments.

\section{Evaluation of neutrophils viability}

The viability of neutrophils was assessed by the MTT assay, similar to the procedures described earlier ${ }^{18,19}$ Briefly, $100 \mu \mathrm{L}$ of the neutrophil suspension $\left(2 \times 10^{6}\right.$ cells $\left./ \mathrm{ml}\right)$ was added to each well of 96 -well microplates and pulsed with $20 \mu \mathrm{L}$ of the MTT solution $\left(5 \mathrm{mg} / \mathrm{mL}\right.$ ) for $4 \mathrm{~h}$ at $37^{\circ} \mathrm{C}$. To dissolve the formazan crystals, $150 \mu \mathrm{L}$ DMSO was added to each well of 96-well microplates and the plates were shaken vigorously. At the end, a microplate reader (Dynatech, Denkendorf, Germany) was used to determine the optical density (OD) at $550 \mathrm{~nm}$. In addition, the experiments were performed in triplicate sets.

\section{Neutral red uptake}

Briefly, $100 \mu \mathrm{L}$ of the neutrophil suspension $\left(2 \times 10^{6}\right.$ cell/ $\mathrm{mL}$ ) was added to each well of 96-well microplates and pulsed with $10 \mu \mathrm{L}$ of the NR solution (0.33\%) for $2 \mathrm{~h}$ at $37^{\circ} \mathrm{C}$. At the end of the incubation period, the medium was discarded and the neutrophils were twice washed in PBS. 
The internalized NR was solubilized for 30-min incubation by mixing $100 \mu \mathrm{L} 10 \%$ acetic acid plus $40 \%$ ethanol solution. The optical density was measured at $550 \mathrm{~nm}$.

\section{Phagocytosis assay}

This experiment was designed as previously described, with some modifications. ${ }^{20}$ In brief, the cells were washed after stationary incubation of neutrophils with opsonized yeast at $37^{\circ} \mathrm{C}$ for $1 \mathrm{~h}$, cytocentrifuged onto glass slides, and fixed in methanol. The slides were stained with MayGrunwald-Giemsa staining. Yeast ingestion was evaluated by light microscopy under oil immersion. Phagocytic activities of neutrophils were reported as percentage of neutrophils, internalized at least one yeast cell.

\section{Respiratory burst}

The NBT reduction assay was used to check the intracellular generation of reactive oxygen species (ROS) by neutrophils. ${ }^{21}$ In brief, neutrophils were incubated for $20 \mathrm{~min}$ with $100 \mathrm{ng} / \mathrm{mL}$ TPA and 0.1\% NBT. The unused NBT was discarded through washing and the reduced dye was extracted in dioxin and quantitated at $520 \mathrm{~nm}$.

\section{Statistical analysis}

The normal distribution of data was confirmed with the Kolmogorov-Smirnov test. Next, the results were analyzed by one-way ANOVA plus Dunnett's post-hoc test and presented as means $\pm \mathrm{SD}$. The minimal level of significance was reported at $\mathrm{p}$ values of less than 0.05 .

\section{Results}

The MTT test showed that MSCs could significantly increase the viability of neutrophils (Fig. 1). Moreover, MSCs pulsed with $0.5 \mathrm{mM}$ of caffeine for $72 \mathrm{~h}$ and MSCs treated with $1 \mathrm{mM}$ of caffeine for 24, 48 and $72 \mathrm{~h}$ significantly diminished the survivability of neutrophils, compared to the control group (the MSCs, which were not pulsed with caffeine) (Fig. 1). These findings suggested that caffeine at high doses can decrease the protective role of MSCs on the viability of neutrophils, so that MSCs treated with $1 \mathrm{mM}$ of caffeine for $72 \mathrm{~h}$ significantly decreased the viability of co-cultured neutrophils compared to neutrophils alone.

As exhibited in Fig. 2, the NR uptake by neutrophils did not show any significant difference between neutrophils alone and neutrophils co-cultured with MSCs without treatment, or the MSCs pulsed with caffeine at concentrations of 0.1 and $0.5 \mathrm{mM}$. However, MSCs treated with caffeine at a concentration of $1 \mathrm{mM}$ significantly lowered the NR uptake by co-cultured neutrophils (Fig. 2).

The phagocytic activity of neutrophils was significantly increased in the neutrophils co-cultured with the MSCs

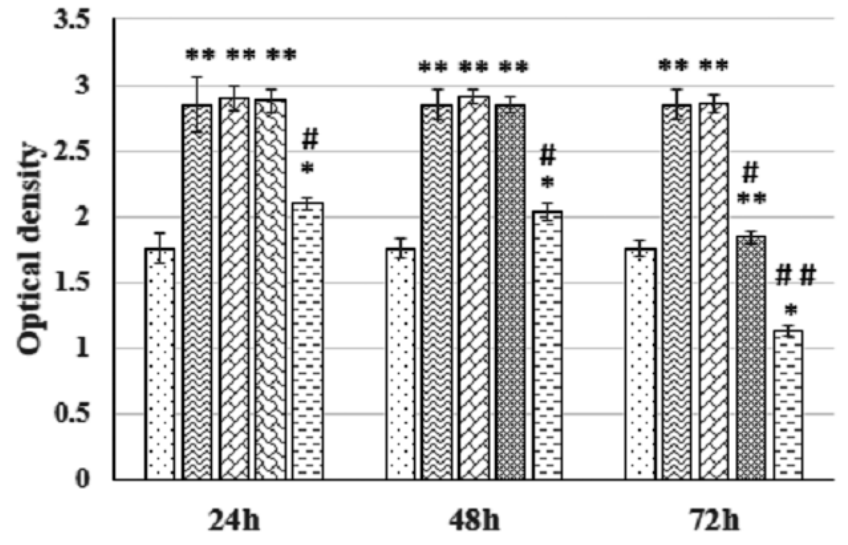

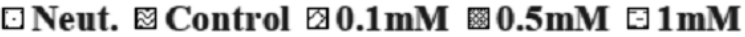

Fig. 1. Effect of caffeine on modulation of the viability of the neutrophils by mesenchymal stem cells (MSCs). MSCs were isolated from bone marrow of rats and pulsed with different concentrations of caffeine ( 0 (control), $0.1,0.5$ and $1 \mathrm{mM})$ at different times $(24,48$ and $72 \mathrm{~h}$ ). Then mesenchymal stem cells co-cultured with neutrophils for $4 \mathrm{~h}$. Greater optical density indicates higher levels of viability. The results showed that caffeine at least at higher doses could significantly decrease the protective role of MSCs on neutrophils apoptosis. Results were shown as mean \pm S.D. Neut. - neutrophils alone, Control - neutrophils co-cultured with of MSCs alone $\left({ }^{*} p<0.01,{ }^{* *} p<0.001\right.$ vs neutrophils alone; $\# p<0.01$, $\#$ \# $<0.001$ vs control)

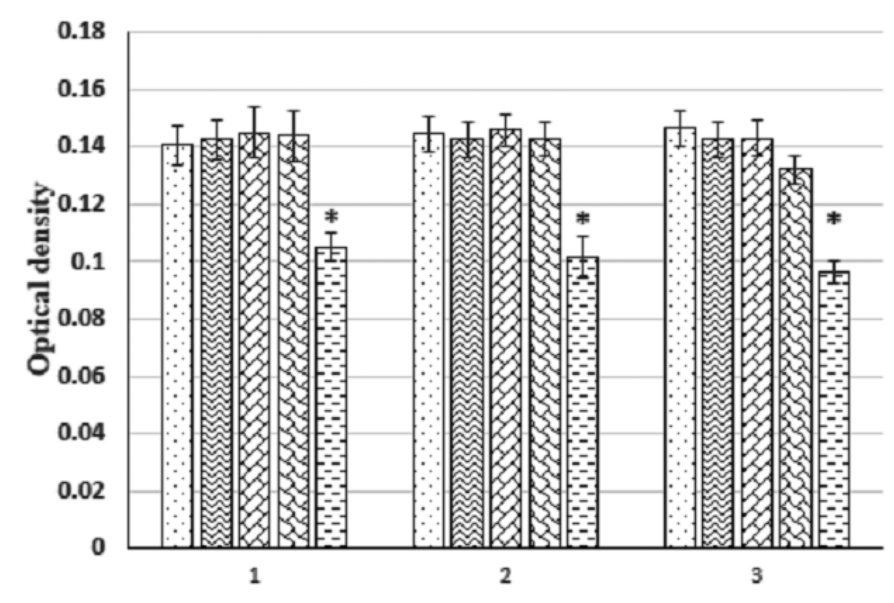

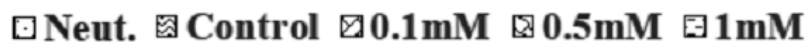

Fig. 2. Modulation of Neutral red uptake by neutrophils. Greater optical density shows higher levels of Neutral red uptake by neutrophils. Results indicated that NR uptake by neutrophils didn't show any significant difference between neutrophils alone and neutrophils co-cultured with MSCs without treatment or MSCs pulsed with caffeine at concentrations of 0.1 and $0.5 \mathrm{mM}$. However, MSCs treated with caffeine at concentrations of $1 \mathrm{mM}$ significantly decreased the NR uptake by co-cultured neutrophils. The values were presented as mean \pm S.D. Neut. - neutrophils alone, Control - neutrophils co-cultured with of MSCs alone $\left(^{*} p<0.001\right.$ vs neutrophils alone or control)

pulsed with caffeine or the MSCs alone, compared to neutrophils without treatment (Fig. 3). The gained results also demonstrated that the phagocytic activity of co-cultured neutrophils and MSCs treated with caffeine was significantly more pronounced than phagocytosis observed by the co-cultured neutrophils and MSCs alone (Fig. 3). 


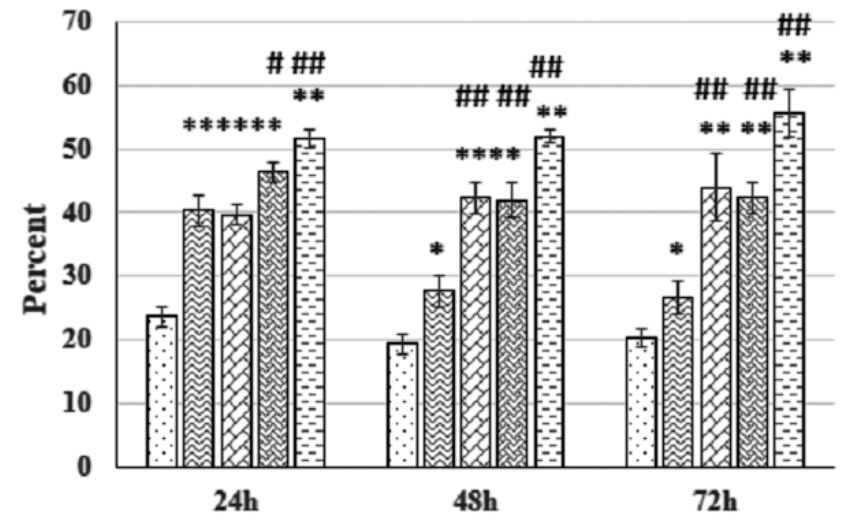

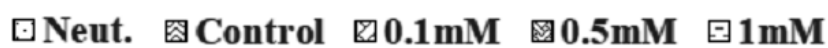

Fig. 3. Modulation of phagocytic ability of opsonized yeast by neutrophils co-cultured with MSCs. Neutrophils were incubated with opsonized yeast at a ratio of 1:10 for $0.5 \mathrm{~h}$ at $37^{\circ} \mathrm{C}$. Greater present value indicates higher levels of phagocytic ability. The phagocytosis activity of neutrophils was significantly increased following co-culture with of MSCs treated with at least $0.5 \mathrm{mM}$ of caffeine for $24 \mathrm{~h}$ compared with control group. Moreover, MSCs treated with caffeine at least at concentration of 0.1 $\mathrm{mM}$ significantly increased the phagocytosis activity of neutrophils after $48 \mathrm{~h}$ and/or $72 \mathrm{~h}$. Neut. - neutrophils alone, Control - neutrophils cocultured with of MSCs alone $\left({ }^{*} p<0.01,{ }^{* *} p<0.001,{ }^{* * *} p<0.0001\right.$ vs neutrophils alone\# $p<001$, \#\# $p<0.001$ vs control)

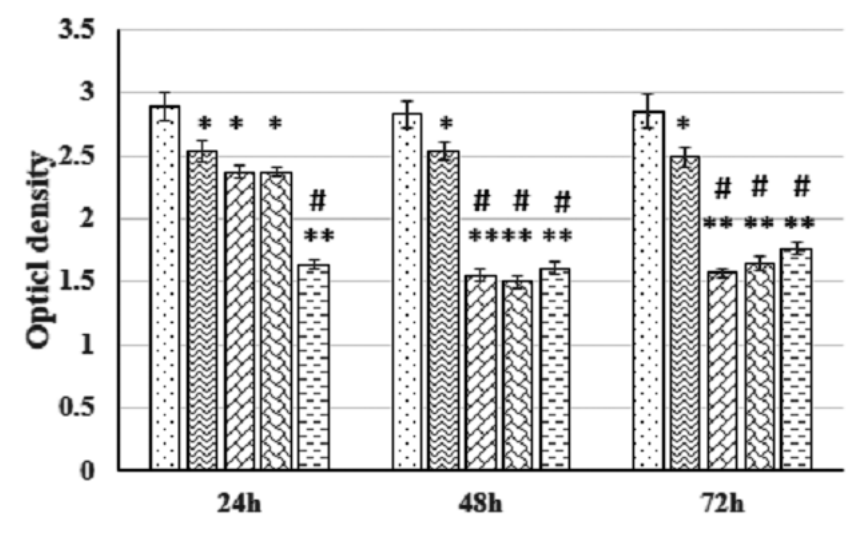

\section{$\square$ Neut. 园Control $\boxminus 0.1 \mathrm{mM} \otimes 0.5 \mathrm{mM} \boxminus 1 \mathrm{mM}$}

Fig. 4. Evaluation of neutrophils respiratory burst after opsonized yeast ingestion by caffeine treated MSCs. Lesser optical density indicates lower levels of respiratory burst. Compared to control group, MSCs pulsed with $1 \mathrm{mM}$ of caffeine for $24 \mathrm{~h}$ and of MSCs treated caffeine even at $0.1 \mathrm{mM}$ for $48 \mathrm{~h}$ and/or $72 \mathrm{~h}$ significantly diminished the rate of respiratory bust of co-cultured neutrophils. Neut. - neutrophils alone, Control - neutrophils co-cultured with of MSCs alone $\left({ }^{*} p<0.01,{ }^{* *} p<0.001\right.$ vs neutrophils alone; $\# \mathrm{p}<0.001$ vs control)

The NBT reduction assay was used to measure the reactive oxygen species (ROS) activity in neutrophils. ${ }^{22}$ The obtained findings expressed that the respiratory burst of neutrophils was significantly decreased in neutrophils co-cultured with the MSCs pulsed or without caffeine, compared to neutrophils without treatment (Fig. 4). The attained data also indicated that this reduction of the respiratory burst is more prominent in the neutrophils co-cultured with caffeine (except caffeine at concentrations of 0.1 or $0.5 \mathrm{mM}$ for $24 \mathrm{~h}$ ) than that observed after co-culture of neutrophils and MSCs alone (Fig. 4).

\section{Discussion}

It has been revealed that MSCs interestingly produce adenosine and express adenosine receptors (A1R, A2AR, $\mathrm{A} 2 \mathrm{BR}$, and A3R), which clearly indicates that adenosine and adenosine receptors play an autocrine or paracrine role in the proliferation and differentiation of MSCs. ${ }^{14,23}$ Adenosine receptors are also differentially expressed in MSCs and involved in lineage-specific differentiation of MSCs. The A2B receptor is dominant in MSCs, and its expression and activity were transiently increased at the early stages of osteoblastic differentiation. During the later stages of osteoblastic differentiation, the expression of A2AR was increased. ${ }^{23}$ On the other hand, differentiation of MSCs to adipocytes is associated with significant up-regulation in A1 and A2A receptors expression. ${ }^{23}$ It has been known for a long time that the methylxanthine derivative, such as caffeine, can interfere with the adenosine/ adenosine receptors biology. 5,6

Neutrophils are the most prominent cell type of the innate immune system and are predominant in host tissues during acute inflammatory processes. ${ }^{11,24}$ Neutrophils may also play an effective role in adaptive immunity. ${ }^{24}$

Mature neutrophils are normally found in the bloodstream and inflamed tissues, instead of bone marrow. Mesenchymal stem cells localized in the perivascular and periendothelial areas can directly crosstalk with neutrophils. ${ }^{25,26}$ It is necessary to notice that MSCs localized in the perivascular area, derived from various tissues, have shown a phenotype similar to that of the bone marrowderived MSCs. ${ }^{26}$ Certainly, the isolation and expansion of MSCs from the bone marrow are easier than isolating MSCs from other tissues. Similar to the present study, some former studies also used the bone marrow derived MSCs to investigate the interaction between MSCs and neutrophils. ${ }^{11,27}$

Neutrophil homeostasis and turnover are highly regulated in the body. Circulating neutrophils have a short life span of 6-10 h, after which the cells undergo apoptosis. ${ }^{28}$ It was shown that MSCs significantly protect neutrophils from apoptosis and increase the life span of these cells. ${ }^{25,29}$ The MTT assay is a rapid test for assessing cell viability. ${ }^{11}$ The findings showed that caffeine at higher doses could significantly decrease the protective role of MSCs on neutrophils apoptosis. Previous studies indicated that MSCs diminish the mitochondrial pro-apoptotic protein, Bax in neutrophils through IL- 6 secretion. ${ }^{27}$ It is also known that adenosine produced by MSCs can stimulate the A2B receptors through autocrine or paracrine routs, and potently stimulates IL- 6 secretion. ${ }^{23}$ According to the antagonistic effects of caffeine on adenosine receptor, it is possible that 
caffeine at higher doses may interfere with IL-6 secretion by MSCs. However, the precise mechanisms involved in these effects are yet to be clarified.

Neutral red can be ingested and accumulated in the lysosomes of neutrophils depending on the level of cell activation. The neutral red uptake by neutrophils depends on different factors connected with cell viability, activity, and cell membrane integrity. ${ }^{30}$

Phagocytosis is an essential function of neutrophils, which participates in the uptake of pathogens, apoptotic bodies, and debris. ${ }^{31}$ The phagocytic activity of neutrophils was markedly increased in neutrophils co-cultured with the bone marrow-derived MSCs compared to neutrophils without MSCs. Moreover, it has been demonstrated that the caffeine treated bone marrow-derived MSCs may cause a significant increase in the phagocytic ability of neutrophils more profound than MSCs alone.

Reactive oxygen species (ROS) are one of the important factors involved in the elimination of invading microbes by neutrophils. ${ }^{22}$ In addition to encountering pathogens, different stimuli may induce the respiratory burst in neutrophils. ${ }^{27}$ Nonetheless, when the production of ROS is excessive or inappropriate, ROS participate in severe host tissue damages and in different immunopathological conditions. ${ }^{32}$ In this survey, it was observed that MSCs could significantly reduce the ROS production by neutrophils. In this regard, the former data indicated that the supernatant of MSCs could inhibit the basal and f-MLP-stimulated production of ROS by neutrophils. ${ }^{27}$ The obtained data also indicated that MSCs pulsed with caffeine could profoundly inhibit the ROS production by neutrophils more pronounced than MSCs without treatment. Of note, higher phagocytic activity without the production of potentially harmful ROS can help phagocytes reduce inflammation.

Our in vitro findings suggest that at least some of the effects of caffeine on the interaction between MSCs and neutrophils may be different between the low to moderate and high concentrations of caffeine. Pervious works also confirmed that caffeine had dose-dependent effects on the osteogenic differentiation of MSCs: $0.1 \mathrm{mM}$ caffeine significantly potentiated mineralization and alkaline phosphatase activity, and upregulated the osteogenic differentiation of MSCs. However, a concentration of caffeine greater than $0.3 \mathrm{mM}$ diminished the osteogenic differentiation of MSCs. ${ }^{3}$ A number of in vitro and in vivo studies have indicated that caffeine could modulate both innate and acquired immune responses. ${ }^{6,33,34}$ Moreover, it has been demonstrated that the effects of caffeine may be partly related to the dose of caffeine. ${ }^{6}$ Interestingly, some evidence has suggested that caffeine, even at the concentrations that are relevant to normal human consumption, may possess anti-inflammatory and immunomodulatory effects. ${ }^{6}$ Based on the attained data, it has been proposed in this paper that some of the immunomodulatory and anti-inflammatory effects of caffeine may be due to the change in the interaction between MSCs and neutrophils.

\section{Conclusions}

The observations in this research suggest that bone marrow derived MSCs pulsed with caffeine at low $(0.1 \mathrm{mM})$ to moderate $(0.5 \mathrm{mM})$ concentrations preserve the basic activity of neutrophils and established the MSCs ability to protect neutrophils from apoptosis. Mesenchymal stem cells treated with caffeine increased the phagocytosis of neutrophils and simultaneously, diminished the production of reactive oxygen substances more profound than MSCs without treatment. Nevertheless, a high concentration of caffeine could interfere with some aspects of the crosstalk between MSCs and neutrophils. Overall, these findings may offer new insight into the potential mechanisms underlying the immunomodulatory and antiinflammatory effects of caffeine.

\section{References}

1. Matissek R. Evaluation of xanthine derivatives in chocolate - nutritional and chemical aspects. Z Lebensm Unters Forsch.1997;205:175-184.

2. Fredholm BB, Battig K, Holmen J, Nehlig A, Zvartau EE. Actions of caffeine in the brain with special reference to factors that contribute to its widespread use. Pharmacological Rev. 1999;51:83-133.

3. Su SJ, Chang KL, Su SH, Yeh YT, Shyu HW, Chen KM. Caffeine regulates osteogenic differentiation and mineralization of primary adiposederived stem cells and a bone marrow stromal cell line. Int J Food Sci Nutr. 2013;64:429-436.

4. Schubert MM, Hall S, Leveritt M, Grant G, Sabapathy S, Desbrow B. Caffeine consumption around an exercise bout: Effects on energy expenditure, energy intake, and exercise enjoyment. J Appl Psychol. 2014;117:745-754.

5. Gorska AM, Golembiowska K. The role of adenosine $A 1$ and $A 2 A$ receptors in the caffeine effect on MDMA-Induced DA and 5-HT release in the mouse striatum. Neurotox Res. 2014.

6. Horrigan LA, Kelly JP, Connor TJ. Immunomodulatory effects of caffeine: Friend or foe? Pharmacol Ther. 2006;111:877-892.

7. Wada N, Gronthos S, Bartold PM. Immunomodulatory effects of stem cells. Periodontology 2000. 2013;63:198-216.

8. Ghannam S, Bouffi C, Djouad F, Jorgensen C, Noel D. Immunosuppression by mesenchymal stem cells: Mechanisms and clinical applications. Stem Cell Res Ther. 2010;1:2.

9. Meirelles Lda S, Fontes AM, Covas DT, Caplan AI. Mechanisms involved in the therapeutic properties of mesenchymal stem cells. Cytokine Growth Factor Rev. 2009;20:419-427.

10. Zhang R, Liu Y, Yan K, et al. Anti-inflammatory and immunomodulatory mechanisms of mesenchymal stem cell transplantation in experimental traumatic brain injury. J Neuroinflammation. 2013;10:106.

11. Esmaili Gouarchin Gale H, Delirezh N, Abtahi Froshani SM, Afzale Ahangaran N. Calcitriol modulates the effects of the supernatants of bone-marrow-derived mesenchymal stem cells on neutrophil functions. Turk J Biol. 2014;38:365-370.

12. Hoogduijn MJ, Cheng A, Genever PG. Functional nicotinic and muscarinic receptors on mesenchymal stem cells. Stem Cells Development. 2009;18:103-112.

13. Zhou Y, Guan XX, Zhu ZL, et al. Caffeine inhibits the viability and osteogenic differentiation of rat bone marrow-derived mesenchymal stromal cells. Br J Pharmacol. 2010;161:1542-1552.

14. Katebi M, Soleimani M, Cronstein BN. Adenosine A2A receptors play an active role in mouse bone marrow-derived mesenchymal stem cell development. J Leukoc Biol. 2009;85:438-444.

15. Duffy MM, Ritter T, Ceredig R, Griffin MD. Mesenchymal stem cell effects on T-cell effector pathways. Stem Cell Res Ther. 2011;2:34.

16. Le Blanc K, Mougiakakos D. Multipotent mesenchymal stromal cells and the innate immune system. Nat Rev Immunol. 2012;12:383-396.

17. Baghaban Eslaminejad M, Nazarian H, Taghiyar L. Mesenchymal stem cell isolation from the removed medium of rat's bone marrow primary culture and their differentiation into skeletal cell lineages. Yakhteh Medical Journal. 2008;10:65-72. 
18. Abtahi Froushani SM, Delirezh N, Hobbenaghi R, Mosayebi G. Synergistic effects of atorvastatin and all-trans retinoic acid in ameliorating animal model of multiple sclerosis. Immunol Invest. 2014;43:54-68.

19. Abtahi Froushani SM, Esmaili Gourvarchin Galeh H. New insight into the immunomodulatory mechanisms of Tretinoin in NMRI mice. IJBMS. 2014;17:632-637.

20. Newman SL, Holly A. Candida albicans is phagocytosed, killed, and processed for antigen presentation by human dendritic cells. Infect Immun. 2001;69:6813-6822.

21. Repine JE, White JG, Clawson CC, Holmes BM. Effects of phorbol myristate acetate on the metabolism and ultrastructure of neutrophils in chronic granulomatous disease. J Clin Invest. 1974;54:83-90.

22. Hamaliaka A, Novikova I. Nitric oxide production disorders in leukocytes of patients with recurrent furunculosis. Biomed Pap Med Fac Univ Palacky Olomouc Czech Repub. 2010;154:163-167.

23. Gharibi B, Abraham AA, Ham J, Evans BA. Adenosine receptor subtype expression and activation influence the differentiation of mesenchymal stem cells to osteoblasts and adipocytes.J Bone Miner Res. 2011;26:2112-2124.

24. Mocsai A. Diverse novel functions of neutrophils in immunity, inflammation, and beyond. J Exp Med. 2013;210:1283-1299.

25. Brandau $S$, Jakob M, Hemeda $H$, et al. Tissue-resident mesenchymal stem cells attract peripheral blood neutrophils and enhance their inflammatory activity in response to microbial challenge. J Leukoc Biol. 2010;88:1005-1015.

26. Crisan M, Yap S, Casteilla L, A perivascular origin for mesenchymal stem cells in multiple human organs. Cell Stem Cell. 2008,3:301-313.

27. Raffaghello L, Bianchi G, Bertolotto M, et al. Human mesenchymal stem cells inhibit neutrophil apoptosis: A model for neutrophil preservation in the bone marrow niche. Stem Cells. 2008;26:151-162.

28. Coxon A, Tang T, Mayadas TN. Cytokine-activated endothelial cells delay neutrophil apoptosis in vitro and in vivo. A role for granulocyte/ macrophage colony-stimulating factor. J Exp Med.1999;190:923-934.

29. Maqbool M, Vidyadaran S, George E, Ramasamy R. Human mesenchymal stem cells protect neutrophils from serum-deprived cell death. Cell Biol Int. 2011;35:1247-1251.

30. Antal P, Sipka S, Surányi P, et al. Flow cytometric assay of phagocytic activity of human neutrophils and monocytes in whole blood by neutral red uptake. Ann Hematol.1995;70:259-265.

31. Greenberg S, Grinstein S. Phagocytosis and innate immunity. Curr Opin Immunol Lett. 2002;12:136-145.

32. Babior BM. Phagocytes and oxidative stress. Am J Med. 2000;109: 33-44.

33. Horrigan LA, Kelly JP, Connor TJ. Caffeine suppresses TNF-alpha production via activation of the cyclic AMP/protein kinase A pathway. Int Immunopharmacol. 2004;4:1409-1417.

34. Senchina DS, Hallam JE, Kohut ML, Nguyen NA, Perera MA. Alkaloids and athlete immune function: Caffeine, theophylline, gingerol, ephedrine, and their congeners. Exerc Immunol Rev. 2014;20:68-93. 